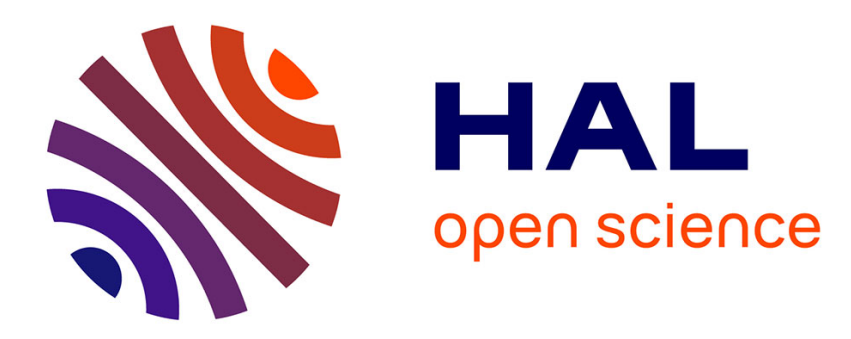

\title{
Ratio of Decrement to Modulus Change for Amplitude-Dependent Internal Friction
}

\author{
A. A. Lebedev
}

\section{To cite this version:}

A. A. Lebedev. Ratio of Decrement to Modulus Change for Amplitude-Dependent Internal Friction. Journal de Physique IV Proceedings, 1996, 06 (C8), pp.C8-325-C8-328. 10.1051/jp4:1996871 . jpa00254679

\section{HAL Id: jpa-00254679 https://hal.science/jpa-00254679}

Submitted on 1 Jan 1996

HAL is a multi-disciplinary open access archive for the deposit and dissemination of scientific research documents, whether they are published or not. The documents may come from teaching and research institutions in France or abroad, or from public or private research centers.
L'archive ouverte pluridisciplinaire HAL, est destinée au dépôt et à la diffusion de documents scientifiques de niveau recherche, publiés ou non, émanant des établissements d'enseignement et de recherche français ou étrangers, des laboratoires publics ou privés. 


\title{
Ratio of Decrement to Modulus Change for Amplitude-Dependent Internal Friction
}

\author{
A.B. Lebedev(1) \\ Department of Physics, University of Illinois, 1110 West Green St., Urbana, IL 61801, U.S.A.
}

\begin{abstract}
The ratio $r$ of the amplitude-dependent decrement $\delta_{h}$ to the amplitude-dependent modulus defect $\Delta M / M$ has been analyzed within the framework of theories of dislocation hysteresis based on both the breakaway Granato-Lücke model and the symmetrical pointed loop frictional model. In the particular case of power laws with the same exponent $n$ for both the decrement and modulus defect: $\delta_{h}=r(\Delta M / M) \propto \sigma_{0}{ }^{n}$, analytical expressions for the relationship between $r$ and $n$ have been derived. The theoretical requirements have been compared with the available experimental data. The use of $r$ for identifying the mechanism of dislocation hysteresis is demonstrated.
\end{abstract}

\section{NTRODUCTION}

A proportionality between the amplitude-dependent decrement $\delta_{\mathrm{h}}$ and the amplitude-dependent modulus defect $\Delta \mathrm{M} / \mathrm{M}$ :

$$
\delta_{\mathrm{h}}=\mathrm{r}(\Delta \mathrm{M} / \mathrm{M})
$$

has been first observed by Read [1,2] in zinc single crystals as early as 1940 and then by many other researchers in a large variety of crystalline solids. Read reported that $r$ in zinc varied with orientation from 0.55 to 5.5. Almost all available experimental data for other materials show the value of $r$ within this range (if the amplitude of vibrational strain $\varepsilon_{0}$ is not very large: $\varepsilon_{0}<10^{-4}$ ). Up to now there is no reasonable theoretical explanation on the orientation dependence of $r$. In the majority of theories main attention has been paid to the decrement, but not to the modulus defect. In order to derive $\Delta \mathrm{M} / \mathrm{M}$ correctly, Fourier analysis should be applied [3]. Granato and Lücke [4] did it for their model and estimated the value of $r$ of the order of unity, however exact formula was not given. Recently Lebedev [5] analyzed the ratio $r$ within the framework of the Granato- Luicke (GL) model. Two conclusions were made: (i) in the general case, $r$ is a function of the vibrational amplitude $\sigma_{0}$, but the value of $r$ should not exceed 2; (ii) for the particular case of a power law

$$
\delta_{\mathrm{h}} \propto \sigma_{0}{ }^{\mathrm{n}}
$$

$r$ does not depend on the amplitude and is a function of $n$ only:

$$
r=2 n /\left[n+2+\frac{2(n+2)}{\pi} B\left(\frac{n+3}{2}, \frac{1}{2}\right)\right],
$$

where $B(x, y)=\Gamma(x) \Gamma(y) / \Gamma(x+y)$ is the beta function and $\Gamma(x)$ is the gamma function.

The aim of the present communication is to analyze the case of frictional hysteresis and to compare theoretical $r(n)$ dependence for three types of hysteresis loops, schematically shown in Fig.1, with the available experimental data. Two types of frictional hysteresis have been considered: (i) Davidenkov pointed loop [6] and (ii) pointed loop with no restoring force (NRF). Lazan [7] gave a description of both types with respect to their damping properties, and actually introduced the term "pointed loops" (in contrast to linear elliptical loops).

(1) Permanent address: Solid State Physics Division, A.F. Ioffe Physico-Technical Institute, Russian Academy of Sciences, 194021 St. Petersburg, Russia. 


\section{THEORY}

Davidenkov [6] suggested that amplitude-dependent internal friction resulted from nonlinear hysteresis of microplastic strain $\varepsilon_{\mathrm{d}}$, and the stress-strain loop had a symmetry axis of the second order (Fig.1b). For a power dependence $\varepsilon_{d}$ on the stress $\sigma$

he derived for the decrement

$$
\varepsilon_{\mathrm{d}}=\left(\sigma+\sigma_{0}\right)^{m}-2^{m-1} \sigma_{0}^{m},
$$

$$
\delta_{\mathrm{h}}=2^{\mathrm{n}+2} \mathrm{nM} \sigma_{0}^{\mathrm{n}} /(\mathrm{n}+2) \text {, }
$$

with $n=m-1$. Eqn.(4) corresponds to the upper branch of the loop, i.e. when the stress increases (a structural sensitive factor here and in what follows is omitted, it does not influence the ratio $r$ ): For more details of the Davidenkov's model see, for example, Lazan [7], Asano[8], and Lebedev and Kustov [9].

The modulus defect can be obtained by substituting $\sigma=\sigma_{0} \cos \Theta$ into Eqn.(4) and using Fourier transformation

$$
(\Delta M / M)=(2 M / \pi) \sigma_{0}^{m-1} \int_{0}^{\pi}(1+\cos \Theta)^{m} \cos \Theta d \Theta .
$$

Eqns. (5) and (6) give the ratio $r$ as

$$
r=2^{n+1} n \pi /\left[(n+2) \int_{0}^{\pi}(\cos \Theta+1)^{n+1} \cos \Theta d \Theta\right] .
$$

Fig.1c shows nonlinear symmetrical NRF loop, The strain $\varepsilon_{d}$ changes only during increasing the absolute value of $\sigma$. If we assume this change to obey a power law, then equation for the upper branch is: $\varepsilon_{d}=\sigma^{m}-\left(\sigma_{0}{ }^{m} / 2\right)$. Using, e.g., Asano's $\delta_{h}-\varepsilon_{d}$ relationship [8] for the decrement and Fourier analysis for the modulus defect, one obtains .

$$
r=\left[(n+1)^{2} \sqrt{\pi} \Gamma\left(\frac{n+1}{2}\right)\right] /\left[(n+2) \Gamma\left(\frac{n+2}{2}\right)\right],
$$

where $n=m-1$, as in the previous case. At $n=0$, i.e for linear NRF loop $(m=1)$, Eqn.(8) gives $r=\pi / 2$. Linear NRF hysteresis leads to amplitude-independent internal friction, as in the case of the LDWRF (limited displacement without restoring force) mechanism suggested by Gremaud [10] to explain peculiarities of internal friction background in solid solution.
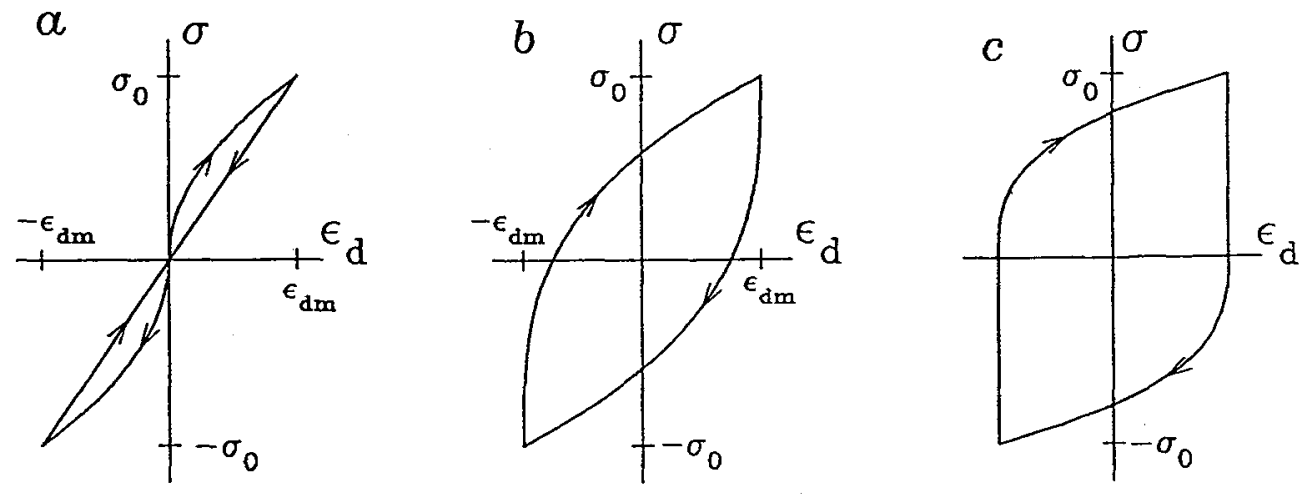

Figure 1. Schematic representation of (a) Granato and Lücke hysteresis, (b) Davidenkov hysteresis, and (c) NRF hysteresis.

\section{COMPARISON WITH EXPERIMENTAL DATA}

Fig.2 shows calculated from Eqns. (3), (7) and (8) curves together with some experimental data [1-3,1121], which are in agreement with Eqns.(1) and (2). Materials and references are listed in Table 1. In spite of a large scatter of data, some regularities can be observed. Points for pure annealed copper are closer to 
Table 1. The ratio $r$ of the amplitude-dependent decrement to modulus defect for various materials in the case of power law: $\delta_{\mathrm{h}}=r(\Delta \mathrm{M} / \mathrm{M}) \propto \sigma_{0}^{n}$.

The symbols have the following meanings: s.-single crystal, p.-polycrystal, eu.-eutectic alloy, $\Theta$ - angle between the normal to basal plane and the sample axis, ann.- annealed, ps.- prestrained, q.-quenched.

\begin{tabular}{|c|c|c|c|c|c|c|c|}
\hline Row & Material & $\begin{array}{c}\text { Impurity } \\
\%\end{array}$ & $\begin{array}{c}\text { Frequency } \\
\mathbf{k H z}\end{array}$ & $T, K$ & $\mathbf{r}$ & $\mathbf{n}$ & Ref. \\
\hline 1 & Cu, s., ps. & 0.002 & 33.5 & room & 4.4 & 2.1 & 2 \\
\hline $\begin{array}{l}2 \\
3 \\
\end{array}$ & $\begin{array}{l}\mathrm{Cu}, \mathrm{s} \text {, ann. } \\
\mathrm{Cu}, \mathrm{s} \text {, ps. }\end{array}$ & 0.01 & $39-78$ & $\begin{array}{c}\text { room } \\
213-306\end{array}$ & $\begin{array}{l}2.2 \\
3.6 \\
\end{array}$ & 2 & 3 \\
\hline $\begin{array}{l}4 \\
5 \\
6 \\
7 \\
\end{array}$ & Cu, s. ann. & $\begin{array}{c}0.01 \mathrm{Si} \\
0.01 \mathrm{Si} \\
0.01 \mathrm{Si} \\
0.005 \mathrm{Ge}\end{array}$ & 80 & $\begin{array}{c}5 \\
81 \\
294 \\
76-210 \\
\end{array}$ & $\begin{array}{l}1.5 \\
1.9 \\
2.9 \\
2.7 \\
\end{array}$ & 2 & 11 \\
\hline 8 & $\mathrm{Cu}-\mathrm{Al}, \mathrm{p}, \mathrm{q}$. & $1.38 \mathrm{Al}$ & 1 & room & 3 & 2.8 & 12 \\
\hline $\begin{array}{c}9 \\
10 \\
11 \\
12 \\
13 \\
\end{array}$ & $\mathrm{Cu}-\mathrm{P}, \mathrm{p}$ & $\begin{array}{l}0.002 \mathrm{P} \\
0.006 \mathrm{P} \\
0.021 \mathrm{P} \\
0.062 \mathrm{P} \\
0.207 \mathrm{P} \\
\end{array}$ & 2.7 & room & $\begin{array}{l}1.8 \\
2.3 \\
2.7 \\
3.1 \\
3.3 \\
\end{array}$ & $\begin{array}{l}1.05 \\
1.44 \\
1.52 \\
1.69 \\
2.05 \\
\end{array}$ & 12 \\
\hline 14 & $\mathrm{Cu}-\mathrm{Si}-\mathrm{Mn}, \mathrm{p} ., \mathrm{ps}$. & $1.6 \mathrm{Si}, 1.4 \mathrm{Mn}$ & 100 & $7-293$ & 1.4 & 1.2 & 13 \\
\hline 15 & Al, s. & $0.66 \mathrm{Si}, 0.22 \mathrm{Fe}$ & 100 & $6.5-293$ & 1.4 & 1.3 & 14,15 \\
\hline 16 & $\mathrm{Al}-\mathrm{Al}_{2} \mathrm{Cu}$, eu. & & 100 & $6.5-293$ & 1.3 & 1.4 & 16 \\
\hline 17 & NaF, s., ps. & 0.01 & 100 & room & 1.8 & 2 & 17 \\
\hline 18 & NaF, s., ps. & 0.01 & 100 & $4.2-295$ & 1.6 & 2 & 18,19 \\
\hline 19 & $\mathrm{MgO}$, s.,ps. & 0.5 & 100 & $65-295$ & 1.2 & 1 & 20 \\
\hline 20 & $\mathrm{Zn}_{\mathrm{n}}, \mathrm{s}, \mathrm{\theta}=0^{0}, \mathrm{ps}$ & 0.003 & 100 & room & 1.6 & 1 & 21 \\
\hline $\begin{array}{l}21 \\
22 \\
23 \\
24\end{array}$ & $\begin{aligned} \text { Zn, s.ann., } \theta & =88^{\circ} \\
\theta & =20^{\circ} \\
\theta & =74.5^{\circ} \\
\theta & =61.3^{\circ}\end{aligned}$ & 0.001 & 39 & room & $\begin{array}{l}0.55 \\
1.4 \\
4.5 \\
5.3\end{array}$ & $\begin{array}{c}1.7 \\
2.9 \\
3 \\
4\end{array}$ & 1 \\
\hline
\end{tabular}

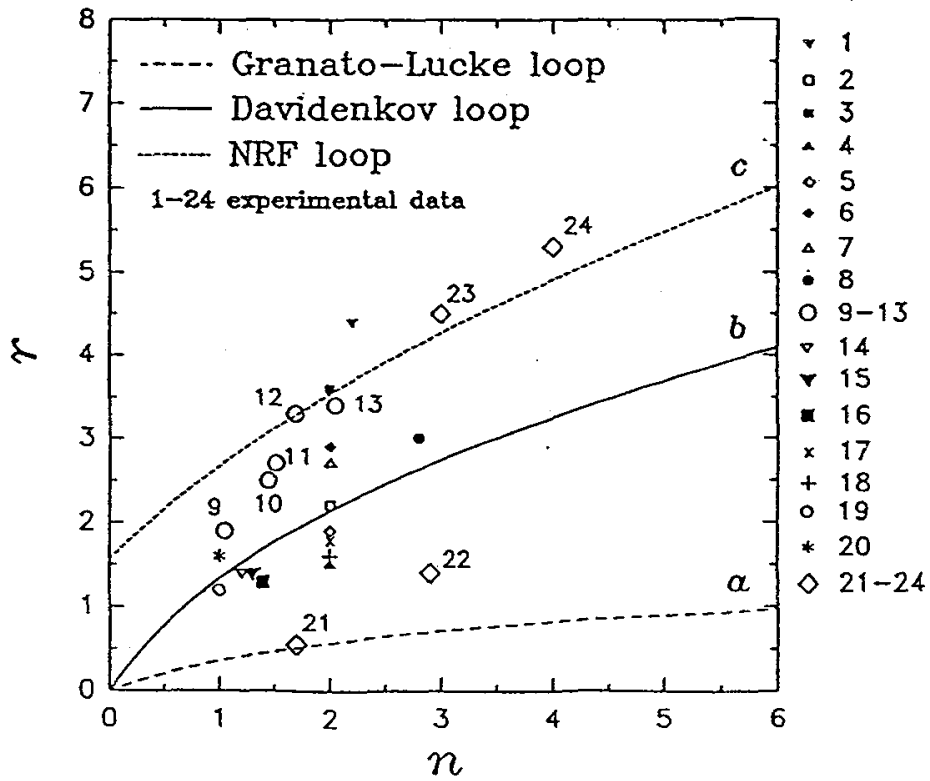

Figure 2. Comparison of $r(n)$ curves calculated for: a - GL (Eqn.3), b - Davidenkov (Eqn.7), and c- NRF (Eqn.8) loops with experimental data for materials listed in Table 1 (numeration of symbols corresponds to numeration of rows). 
the Davidenkov loop, whereas prestrained copper fits the NRF curve. Crystals with the $\mathrm{NaCl}$ structure (rows 17-19) are closer to the Davidenkov loop, which is in agreement with direct measurement of stressstrain loops at low $(0.5 \mathrm{~Hz})$ frequencies [22] and with the loops obtained at higher frequencies $(40 \mathrm{kHz}$ [23] and $128 \mathrm{~Hz}$ [24]) from the dislocation polarization signal.

Dependence of $r$ on orientation in zinc (rows 21-24 in Table 1) can be interpreted in terms of changing the mechanism of hysteresis from the GL breakaway (for pyramidal dislocations) to the NRF loop (for basal plane). Results of Golyandin and Kustov [25] on direct measurement of $\sigma-\varepsilon_{\mathrm{d}}$ loops at $0.5 \mathrm{~Hz}$ in zinc single crystals, oriented for basal slip, show features of the NRF hysteresis.

The origin of the restoring force in the GL model is the dislocation line tension [4]. In the frictional hysteresis of the Davidenkov loop type, the line tension and/or long-range internal stresses may play an important role as a source of the restoring force [26,27].

\section{Acknowledgments}

The work was done during the author's stay as a Visiting Researcher at the University of Illinois at Urbana-Champaign (UIUC) and was supported by NSF Grant DMR 93-19773. The author is very grateful to Prof. A.V. Granato for his interest in this work and for stimulating discussions. The help of Elena Pourmal (MRL Computer Center, UIUC) is also gratefully acknowledged.

\section{References}

1. Read T.A., Phys. Rev. 58 (1940) 371-380.

2. Read T.A., Trans. AIME 143 (1941) 30-41.

3. Nowick A.S., Phys. Rev. 80 (1950) 249-257.

4. Granato A.V., Lücke K., J. Appl. Phys. 27 (1956) 583-593.

5. Lebedev A.B., Philos. Mag. A 74 (1996) 137.150.

6. Davidenkov N.N., Zh. Tekh. Fiz. 8 (1938) 483-499.

7. Lazan B., Damping of materials and members in structural mechanics (Pergamon Press, Oxford, 1968).

8. Asano S. J. Phys. Soc. Japan 29 (1970) 952-963.

9. Lebedev A.B., Kustov S.B., Phys. Stat. Sol. (a) 136 (1993) K85-K88.

10. Gremaud G, J. Physique (Paris) 48 (1987) C8-15 - C8-30.

i i. Saui K.H., Bauer C.L., J.Appl.Phys. 39 (1968) 1469-1477.

12. Takahashi S., J.Phys.Soc.Japan 11 (1956) 1253-1261.

13. Lebedev A.B., Pilecki S, Scripta Met. Mater. 32 (1995) 173-178.

14. Lebedev A.B., Fiz.Tverd.Tela 34 (1992) 1889-1896 [Sov.Phys.Sol.State 34 (1992) 1008-1012].

15. Lebedev A.B., Ivanov V.I., Mat.Sci.Forum 119-121 (1993) 245-250.

16. Lebedev A.B., Nikanorov S.P. Fiz.Tverd.Tela 38 (1996) 839-850 [Phys.Sol.State 38 (1996) 465-471].

17. Lebedev A.B., Kustov S.B., Kardashev B.K., Fiz.Tverd.Tela 31 (1989) 62-68 [Sov.Phys.Sol.State 31 (1989) 34-38].

18. Kardashev B.K., Nikanorov S.P., Voinova O.A., Fiz.Tverd.Tela 16 (1974) 1068-1072 [Sov. Phys. Sol. State 16 (1974) 687-689].

19. Nikanorov S.P., Kardashev B.K., Elasticity and dislocation anelasticity of crystals (Nauka, Moscow, 1985) (in Russian).

20. Kardashev B.K., Kustov S.B., Lebedev A.B., Berezhkova G.V., Perstnev P.P., Appel F., Messerschmidt U., Phys.Stat.Sol.(a) 91 (1985) 79-87.

21. Lebedev A.B., Burenkov Yu.A., Golubenko T.I., Fiz.Tverd.Tela 35 (1993) $420-430$ [Phys. Sol. State 35 (1993) 216-221].

22. Kustov S.B., Golyandin S.N., Kardashev B.K., Mat.Sci.Forum 119-121 (1993) 239-244.

23. Robinson W.H., Philos. Mag. 25 (1972) 355-369; Philos. Mag. A 43 (1981) 967- 977.

24. Tanibayashi M., J.Phys.Soc.Japan 45 (1978) 1063-1064; ibid. 48 (1980) 890-897.

25. Golyandin S.N., Kustov S.B., J. Alloys Comp. 211-212 (1994) 164-168.

26. Kressel H., Brown N., Dislocation Dynamics, Ed. by A.R. Rosenfield, G.T. Hahn, A.L. Bement Jr. and R.I. Jaffee (McGraw Hill, New York, 1968) 337- 354.

27. Ishii K., J.Phys.Soc.Japan 52 (1983) 141-148. 